\title{
Ground Gamma Ray (GGR) activity associated with rain and lightning
}

\author{
U. B. Jayanthi ${ }^{1}$, A. A. Gusev ${ }^{3}$, J.A.C.F. Neri ${ }^{1}$, T.Villela ${ }^{1}$, Pinto Jr. ${ }^{1}$, G. I. Pugacheva ${ }^{2}$, K. C. Talavera ${ }^{1}$ and I.M. Martin ${ }^{4}\left({ }^{\star}\right)$
}

1. Instituto Nacional de Pesquisas Espaciais (INPE), Sao Jose dos Campos, SP, Brazil.

2. Unidade Regional Sul de Pesquisas Espaciais, INPE, Santa Maria, RS, Brazil.

3. Space Research Institute of the Russian Academy of Science (IKI), Moscow, Russia.

4. Universidade de Taubaté (UNITAU), Taubaté, SP, Brazil.

Copyright 2005, SBGf - Sociedade Brasileira de Geofísica

This paper was prepared for presentation at the $9^{\text {th }}$ International Congress of the Brazilian Geophysical Society held in Salvador, Brazil, 11-14 September 2005.

Contents of this paper were reviewed by the Technical Committee of the $9^{\text {th }}$ International Congress of the Brazilian Geophysical Society. Ideas and concepts of the text are authors' responsibility and do not necessarily represent any position of the SBGf, its officers or members. Electronic reproduction or storage of any part of this paper for commercial purposes without the written consent of the Brazilian Geophysical Society is prohibited.

\begin{abstract}
The naturally occurring environmental Ground Gamma Radiation (GGR) is established as due to the radon progeny and efforts are continuously being made to detect the associated increases in GGR due to rain precipitation and lightning phenomena. We have installed, a Gamma radiation monitoring system with the detector equipment situated within a distance of 100 meters from two rocket launch towers for induced lightning. The detector, a Nal (TI) crystal of $40 \mathrm{~cm}$ dia., is monitored on a continuous basis every $10 \mathrm{~s}$ in the energy range of 50 $\mathrm{keV}$ to $\sim 1 \mathrm{MeV}$. The precipitation rates, electrical field parameters etc., are available at the site. The system is in operation since February 2005, and has produced data during events corresponding to rain precipitation and lightning activity and the preliminary results will be presented.
\end{abstract}

\section{Introduction}

Gamma rays detected on the surface of Earth monitors gamma rays due to surface exhalation of radon progeny. During normal times, gamma count rate (GCR) variation due to diurnal modulation is observed and the percentage variation is relatively small. Investigations of seasonal variations and increases due to tectonic activity are also being done. The more interesting aspect of the gamma measurements concern the association with rain and snow precipitation (Greenfield et. al., 2001, 2003 and Dwyer et al, 2004)). In recent times, interest to observe gamma rays at times of to lightning phenomena is being sought out by satellite and ground observations (Smith et al, 2005).

All observations till now conducted systematically, have employed 3 inch or less dia. detector systems of laboratory use. As such for extracting details of the gamma ray increases due to the various geophysical phenomena, we have set up a large area detector system and monitoring on continuous basis since February, 2005. We report here our detector system and the preliminary observations.

\section{Method}

The experiment utilizes for the monitoring of the gamma rays a large area crystal of $\mathrm{Nal}(\mathrm{TI})$ employed as an Anger camera, in imaging of cosmic gamma ray sources in balloon experiments (Villela et al, 1994 ) of dimensions of $40 \mathrm{~cm}$ diameter and $5 \mathrm{~cm}$ thick, and is viewed by 19 photomultipliers. This principal detector is surrounded by scintillators of $\mathrm{Nal}(\mathrm{TI})$ on the bottom and of plastic well on the sides, to reject extraneous back ground events. However, in our monitoring experiment this anti shield is not utilized for active rejection of back ground but only as a passive system. A thick aluminum housing acted as a support to the detectors and also as an hermetic shield.

Standard electronic equipment consisted of high voltage units for the photomultipliers and pre-amplifiers. An Ortec PCA card is utilized for the monitoring of the pulse height of the combined signal response of the 19 PM's. The PHA data of 256 channels encompassing the energy range of $50 \mathrm{keV}$ to $1 \mathrm{MeV}$ is continuously monitored every $10 \mathrm{~s}$ and the data is acquired by a Personal Computer into memory unit. The electronics units are protected against all electrical transients utilizing Faraday cages, lightning protectors, electrical surge impedance etc. Besides, the electrical supply is provided through a nobreak and battery power up system.

The data is retrieved for analysis once in a week along with the rain precipitation data and other information. A GPS system provides the time stamping every day.

This whole system mounted on an aluminum frame is protected against wind and rain by wood and further protected with plastic sheet. The detector is situated about 3 meters above the ground level.

\section{Localization and advantages of the experiment}

1. The experimental set up is placed in an open field, well insulated against electrical noises, in the INPE Campos at Cachoeira Paulista (CP), São José dos Campos, SP, Brazil. The site is interesting as it is situated in the rain forest valley region of Brazil. The instrument is localized, 100 meters away in between two towers of rocket launchers which produce artificial lightning phenomena. Essentially five months span the rainy season and the artificial lightning inducing rocket launches are conducted for 4 month period approximating at least 10 launches a year. The lightning activity is photographed in the field and well documented.

2. The motivation in our instrumental construction, the acquisition of statistically very significant pulse height data every $10 \mathrm{~s}$ (later this is expected to be decreased still lower) can provide quantitative details involved in the emission of gamma rays due to the different geophysical phenomena. Additionally all ancillary data like electrical conductivity, electric field intensities of cloud and rain precipitation are available. The INPE Atmospheric 
Electrical group has a monitor system for the localization of natural lightning phenomena around the local.

\section{Results}

This experimental set up was positioned in the filed almost at the end of the both rocket launch and rain precipitation season. We devoted a good time in the run of the set up initially, and insured and verified against all the electrical transients and discharge phenomenon that effect the electronics and data collection.

We started acquiring the gamma ray data since February 2005, and we show below some examples of the preliminary data in connection with rain and lightning. We have not still started the systematic and detailed analysis.

Clearly the diurnal variation tendency in the 24 hour period in the gamma ray count rate is noted and the maximum corresponding to increases in the after noon times.

The experiment monitored rain precipitation during many storm times since February.

In figure $1 \mathrm{a}$ and $\mathrm{b}$, we show some examples of rain associated gamma ray increases. The plot shows the increases of gamma ray counts for every $10 \mathrm{~s}$ interval against the universal time. The precipitation rate is shown as a continuous line. Clear association is noted between rain and excess of GGR rate.
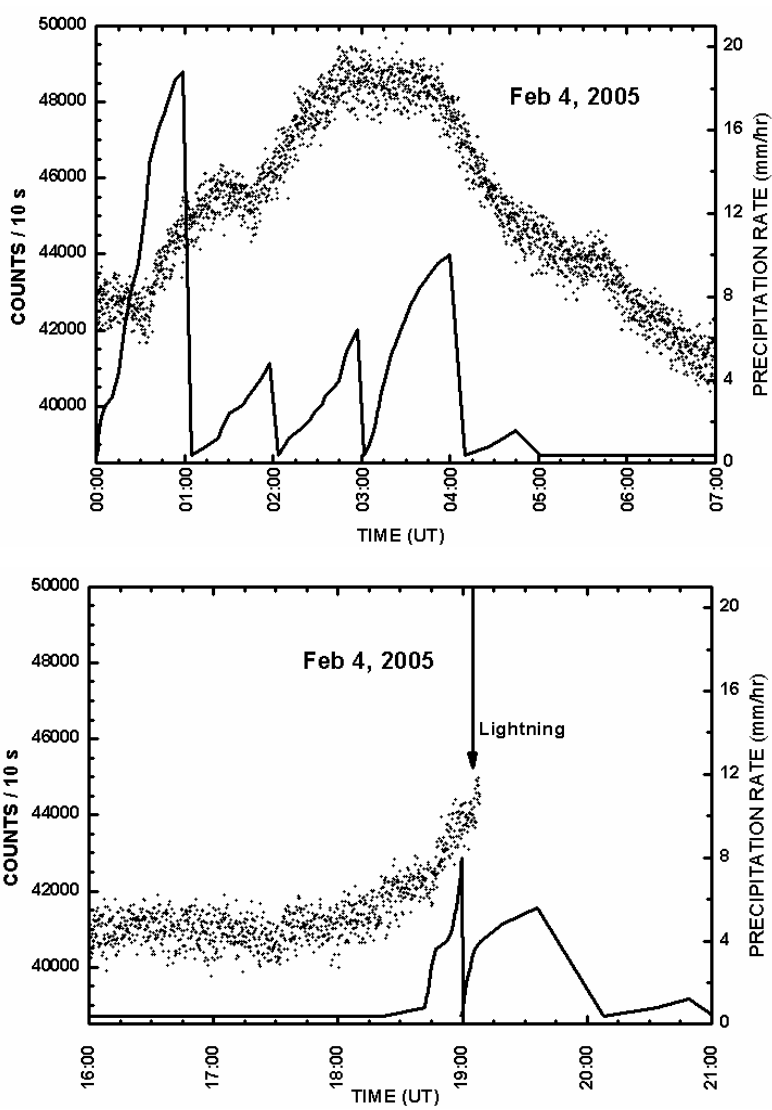

Fig. 1 (a): The increases of gamma ray counts in intervals of $10 \mathrm{~s}$ (points) show clear association with rain recipitation rate( line) during 7 hour period on Febraury 4, 2005. (b): Gamma ray increases with rain precipitation.
Also in February, two rocket launches for the artificial lightning were conducted. During the launch interval (which may last 3 to 4 hours), the procedure consisted of running the gamma ray experiment on the storage batteries, so as to prevent any kind of interference due to electrical transient associated with power line and supply. In both the rocket launch occasions the subsequent data analysis showed the batteries could not supply electrical power for periods greater than 3 hours to the instrument. In the lightning on February 4(Figure 2a), few minutes after the launch, the system till then running for more than 4 hours, stopped producing data and investigations showed that it as due to lack of supply from batteries and ruled out any transient association due to the launch. In the second launch, on February 19, the data was collected till 1 hour after the launch (Figure 2b).
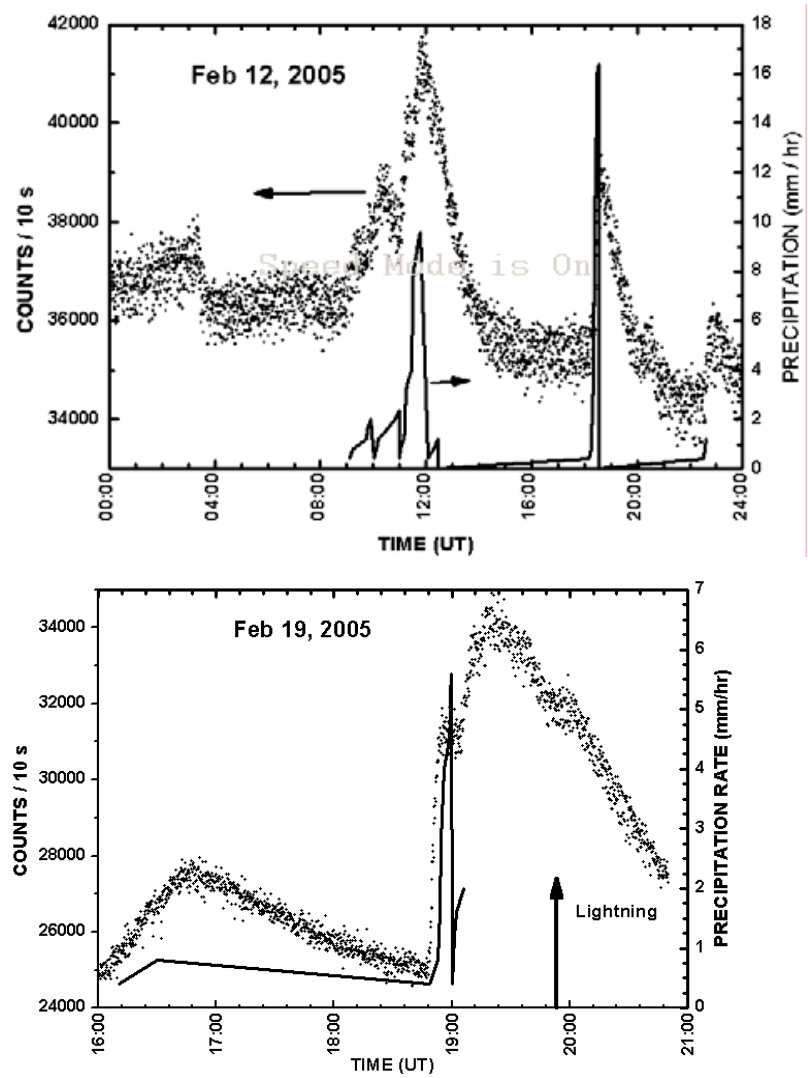

Figure 2: (a) Gamma ray counts and rain precipitation data on Feb 4, and (b) on Feb 19, when artificial lightning were produced (vertical arrows). The top figure shows termination of gamma ray data after launch and in bottom figure an hour after launch due to battery supply exhaust. Acknowledgments

The experiment are due to the efforts of Luiz E. Almeida, Marcos Okada and Edson R. Silva. We acknowledge the advise and support of Mr. André Eybert-Berard of Indelec, France and the personnel of CPTEC, INPE for providing the precipitation data.

\section{References}

Dwyer et al., GRL, 31, L12102, 2004.

Grenfield et al., J. Appl. Phys., 91(3), 1628, 2002.

Grenfield et al., J. Appl. Phys., 93(9), 5733, 2003.

Smith et al., Science, 307, 1085, 2005.

Villela et al., Astrophys. Space Sci., 214, 161, 1994. 